\title{
Chemokine-mediated inflammation in the degenerating retina is coordinated by Müller cells, activated microglia, and retinal pigment epithelium
}

Matt Rutar ${ }^{1,2^{*}}$, Riccardo Natoli ${ }^{1,2}$, RX Chia ${ }^{1}$, Krisztina Valter ${ }^{1,2}$ and Jan M Provis ${ }^{1,2}$

\begin{abstract}
Background: Monocyte infiltration is involved in the pathogenesis of many retinal degenerative conditions. This process traditionally depends on local expression of chemokines, though the roles of many of these in the degenerating retina are unclear. Here, we investigate expression and in situ localization of the broad chemokine response in a light-induced model of retinal degeneration.

Methods: Sprague-Dawley (SD) rats were exposed to 1,000 lux light damage (LD) for up to 24 hrs. At time points during ( 1 to 24 hrs) and following (3 and 7 days) exposure, animals were euthanized and retinas processed. Microarray analysis assessed differential expression of chemokines. Some genes were further investigated using polymerase chain reaction (PCR) and in situ hybridization and contrasted with photoreceptor apoptosis using terminal deoxynucleotidyl transferase dUTP nick-end labeling (TUNEL). Recruitment of retinal CD45 leukocytes was determined via fluorescence activated cell sorting (FACS), and expression of chemokine receptors determined using PCR.
\end{abstract}

Results: Exposure to 24 hrs of LD resulted in differential expression of chemokines including $\mathrm{CCl} 3, \mathrm{CCl} 4, \mathrm{Ccl} 7, \mathrm{CxCl}$, and Cxcl10. Their upregulation correlated strongly with peak photoreceptor death, at 24 hrs exposure. In situ hybridization revealed that the modulated chemokines were expressed by a combination of Müller cells, activated microglia, and retinal pigment epithelium (RPE). This preceded large increases in the number of $\mathrm{CD}_{4} 5^{+}$cells at 3- and 7-days post exposure, which expressed a corresponding repertoire of chemokine receptors.

Conclusions: Our data indicate that retinal degeneration induces upregulation of a broad chemokine response whose expression is coordinated by Müller cells, microglia, and RPE. The findings inform our understanding of the processes govern the trafficking of leukocytes, which are contributors in the pathology of retinal degenerations.

\section{Background}

Chemokines are a large family of genes whose potent chemoattractant properties help drive the recruitment of leukocytes during immune surveillance and inflammation. When induced, chemokines form gradients that establish directional cues for leukocytes - such as monocytes - to sites of injury, and aid their arrest and extravasation into the parenchyma [1]. Chemokines are grouped according to the relative position of their first

\footnotetext{
* Correspondence: matt.rutar@anu.edu.au

'John Curtin School of Medical Research, The Australian National University, Building 131, Garran Road, Canberra ACT 2601, Australia

${ }^{2}$ ANU Medical School, The Australian National University, 54 Mills Road, Canberra ACT 2601, Australia
}

$\mathrm{N}$-terminal cysteine residues, comprising $\mathrm{C}$ ( $\gamma$ chemokines), CC ( $\beta$ chemokines), CXC ( $\alpha$ chemokines), and CX3C ( $\delta$ chemokines) families $[2,3]$. They exert their biological activity through binding cell surface chemokine receptors, which are part of the superfamily of seven transmembrane domain receptors consisting of $\mathrm{C}, \mathrm{CC}, \mathrm{CXC}$, and $\mathrm{CX} 3 \mathrm{C}$ receptor subclasses [2].

Monocyte recruitment is a well-characterized feature in retinal pathologies including age-related macular degeneration (AMD) [4-7], retinitis pigmentosa [5], retinal detachment [8,9], glaucoma [10-12], and diabetic retinopathy $[10,13]$. In some instances such recruitment proves more detrimental than fortuitous, and monocyte aggregation is directly implicated in retinal models of 
neovascular-AMD [14], light-induced damage [15-17], diabetic retinopathy $[18,19]$, and glaucoma $[20,21]$. Chemokine signaling is believed to play a role in mediating monocyte migration in several CNS disorders including multiple sclerosis, Alzheimer's disease, and brain ischemia and trauma (reviewed in [2,22-24]). In the retina, upregulation of $\alpha$ and $\beta$ chemokines, such as $\mathrm{Ccl} 2$, Cxcl1, and Cxcl10 have been detected by gene expression analyses in both wet and dry forms of age-related macular degeneration (AMD) [25]. Ccl2 is particularly wellcharacterized in the retina, and knockout studies indicate that ablation of $\mathrm{Ccl} 2$ or its receptor $\mathrm{Ccr} 2$ reduces monocyte infiltration and retinal degeneration in experimental choroidal neovascularization (CNV) $[26,27]$ and in lightdamaged $\mathrm{Cx}_{3} \mathrm{Cr}^{-/-}$mice [28]. Additionally, we have shown that expression of $\mathrm{Ccl} 2$ is upregulated in Müller cells in light-induced retinal degeneration [29], and targeted knockdown of $\mathrm{Ccl} 2$ with siRNA reduces recruitment of microglia/monocytes and photoreceptor death [30].

Despite a growing understanding of the $\mathrm{Ccl} 2$ axis in relation to retinal dystrophies, there is a relative paucity in knowledge of the greater chemokine milieu of the retina and the cellular events that contribute to their expression. In this study, we aimed to investigate transcriptional regulation and spatiotemporal distribution of the chemokine response in the retina in situ, following lightinduced degeneration. We find that multitude $\alpha$ and $\beta$ chemokines are upregulated following light damage, in correlation with photoreceptor death. Further, we show, using in situ hybridization, that a coordinated trio of Müller cells, retinal pigment epithelium (RPE), and microglia express a suite of $\alpha$ and $\beta$ chemokines following injury, for which recruiting $\mathrm{CD} 45^{+}$cells bear corresponding chemokine receptors.

\section{Methods}

\section{Animals and light damage paradigm}

All experiments conducted were in accordance with the ARVO Statement for Use of Animals in Ophthalmic and Vision Research; the study was approved by the Animal Experimentation Ethics Committee (AEEC) of the Australian National University (R.BSB.05.10). Young adult Sprague-Dawley (SD) rats aged were exposed to 1,000 lux of light damage (LD) following a previous protocol [31]. Animals were exposed to LD in increments of $1,3,6,12,17$, or 24 hrs. Additionally, some animals were returned to dim-light (5 lux) conditions immediately following $24 \mathrm{hrs}$ of LD for a period of 3 or 7 days, to assess post exposure changes. All time points were compared back to age-matched, dim-reared animals.

\section{Tissue collection and processing of whole retinas}

Animals were euthanized using an overdose of barbiturate, which was administered via intraperitoneal injection
(Valabarb; Virbac, NSW, Australia). The left eye from each animal was marked for orientation then enucleated for cryosectioning $(n=6)$, while the retina from the right eye was excised through a corneal incision for RNA extraction $(n=6)$. Retinas were processed using previously described protocols [31].

\section{Fluorescence-activated cell sorting of retinal microglia}

Rats at each time point were euthanized as described previously. Retinas from both eyes were promptly removed through a corneal incision. Retinas from each animal were pooled and immediately placed in chilled Hank's balanced salt solution (HBSS) ( $\mathrm{n}=5$ per time point) and then subjected to light mechanical separation using a razor blade. Samples were transferred into 0.2\% papain digestion cocktail as described in a previous protocol [32] with minor modifications, and incubated at $8^{\circ} \mathrm{C}$ for 45 minutes, then $28^{\circ} \mathrm{C}$ for 7 minutes. The resulting homogenate was centrifuged at $250 \mathrm{~g}$ for $5 \mathrm{mi}-$ nutes at $4^{\circ} \mathrm{C}$, and the pellet was resuspended in neutralization buffer [32]. The homogenate was centrifuged again at $420 \mathrm{~g}$ for 5 minutes at $4^{\circ} \mathrm{C}$, and the pellet resuspended in staining buffer containing $1.0 \%$ bovine serum albumin (BSA), and $0.1 \%$ azide. The samples were incubated in staining buffer containing a CD45 antibody conjugated to Alexa 647 (Biolegend, San Diego, CA, USA) for 45 minutes at $4^{\circ} \mathrm{C}$, then washed twice in HBBS and resuspended in staining buffer. The resultant CD45stained samples were run through a fluorescence-activated cell sorter (FACS) (BD FACSAria II; BD Biosciences, Franklin Lakes, NJ, USA). Viability of the sorted cells was assessed by labeling with DAPI. The isolated $\mathrm{CD} 45^{+}$cells were collected in staining buffer and kept chilled on ice until RNA extraction could be commenced.

To prepare for RNA extraction, isolated samples were centrifuged at $420 \mathrm{~g}$ for 5 minutes at $4^{\circ} \mathrm{C}$, and the supernatant removed. RNA extraction was performed with a combination of TRIzol Reagent (Life Technologies, Carlsbad, CA, USA) and an RNAqueous-small scale kit (Life Technologies, Carlsbad, CA, USA) utilized in tandem to extract and purify the RNA respectively, as described previously [33]. Isolated total RNA was analyzed for quantity and purity with a ND-1000 spectrophotometer (Nanodrop Technologies, Wilmington, DE, USA).

\section{Microarray experimentation and analysis}

Microarray analysis of RNA from whole retinas was conducted using raw microarray data derived from an investigation by our group [31], using Rat Gene 1.0 ST arrays (Affymetrix, Santa Clara, CA, USA); the microarray data is accessible from the NCBI Gene Expression Omnibus repository (GSE22818). Analysis compared samples from dim-reared and 24-hrs of LD experimental groups $(n=3$ for each). The microarray data was analyzed with Partek 
Genomics Suite 6.4 software (Partek Inc., St. Louis, MO, USA), using the same parameters as in our previous investigation [31].

Statistical analysis was conducted using the analysis of variance (ANOVA) statistic with the threshold of significance set at $P<0.05$, with a differential expression cut-off of $>50 \%$. The differentially expressed genes were screened for those pertaining to chemokine activation, and were grouped according to pathway information summarized from the Gene Ontology Consortium [34].

\section{Polymerase chain reaction}

Quantitative real-time polymerase chain reaction (qPCR) was used to validate the expression of genes identified in the microarray analysis, over the protracted light damage time course $(n=6)$. First-strand cDNA synthesis was performed as described previously [29]. Expression was measured using commercially available TaqMan hydrolysis probes (Life Technologies, Carlsbad, CA, USA); the particulars are provided in Table 1 . The hydrolysis probes were applied in the same fashion as our previous study [29]. Fold change was determined using the $\Delta \Delta \mathrm{C}_{\mathrm{q}}$ method, where the expression of the target gene was normalized relative to the expression of the reference gene glyceraldehyde-3-phosphate dehydrogenase (GAPDH). Expression of GAPDH does not change with respect to retinal light damage, as indicated by several investigations [31,35,36].

Standard PCR was performed on RNA samples purified from FACS-isolated monocytes/microglia, using primers specific to chemokine receptor genes (Table 2). Primers were designed using the Primer3 web-based design program [37], and tailored to transverse an intron splice site. First-strand cDNA synthesis was performed from $50 \mathrm{ng}$ of RNA using the Tetro cDNA synthesis kit (Bioline, London, UK), and applied according to the manufacturer's instructions. Standard PCR was then conducted on the samples using MyTaq DNA polymerase; the presence of PCR product and specificity of the reaction were assessed by gel electrophoresis.

\section{In situ hybridization}

A number of chemokines ( $\mathrm{Ccl} 3, \mathrm{Ccl} 4, \mathrm{Ccl} 7, \mathrm{Cxcl} 1$, and Cxcl10) were cloned from PCR products (540-bp, 212bp, 540-bp, 487-bp, and 504-bp amplicons, respectively) using cDNA prepared from rat retinas (as described in the qPCR section). Cloning was performed using the pGEM-T DNA vector system (Promega, Madison, WI, USA) and JM109 competent E.coli (Promega, Madison, WI, USA). A DIG RNA Labeling Kit SP6/T7 (Roche, Basel, Switzerland) was used to transcribe linearized plasmid and generate DIG-labeled antisense and sense riboprobes. The in situ hybridization was performed using a previously established protocol [38]; individual riboprobes were hybridized overnight at $57^{\circ} \mathrm{C}$ and then washed in decreasing concentrations of saline sodium citrate $\left(\mathrm{pH} \mathrm{7.4)}\right.$ ) at $60^{\circ} \mathrm{C}$. The bound probe was visualized with either NBT/BCIP or HNNP/Fast-Red (Roche, Basel, Switzerland).

Following hybridization, sections stained with HNNP/ Fast-Red were also counter-stained using immunohistochemistry. In situ-stained sections were incubated with primary antibody overnight at $4^{\circ} \mathrm{C}$, which was raised against either IBA1 (1:500; Wako, Osaka, Japan), Vimentin (1:100; Sigma-Aldrich, St. Louis, MO, USA), or RPE65 (1:200; Abcam, Cambridge, UK). Sections were then incubated with biotinylated antibodies raised against either rabbit or mouse IgG's (Life Technologies, Carlsbad, CA, USA) for 2 hrs at room temperature and followed by incubation in streptavidin conjugated to Alexa488 (Life Technologies, Carlsbad, CA, USA) for 1.5 hours at room temperature. Slides were then cover slipped with Aqua Poly/Mount (Polysciences, Warrington, PA, USA), and

Table 1 Taqman hydrolysis probes

\begin{tabular}{|c|c|c|c|}
\hline Gene symbol & Gene name & Catalog & Entrez Gene ID \\
\hline CCL3 & Chemokine (C-C motif) ligand 3 & Rn00564660_m1 & NM_013025.2 \\
\hline CCL4 & Chemokine (C-C motif) ligand 4 & Rn00587826_m1 & NM_053858.1 \\
\hline CCL7 & Chemokine (C-C motif) ligand 7 & Rn01467286_m1 & NM_001007612.1 \\
\hline CXCL1 & Chemokine (C-X-C motif) ligand 1 & Rn00578225_m1 & NM_030845.1 \\
\hline CXCL10 & Chemokine (C-X-C motif) ligand 10 & Rn01413889_g1 & NM_139089.1 \\
\hline CXCL11 & Chemokine (C-X-C motif) ligand 11 & Rn00788262_g1 & NM_182952.2 \\
\hline ADAM17 & ADAM metallopeptidase domain 17 & Rn00571880_m1 & NM_020306.1 \\
\hline IL1B & Interleukin $1 \beta$ & Rn00580432_m1 & NM_031512.2 \\
\hline MYD88 & Myeloid differentiation primary response gene 88 & Rn01640049_m1 & NM_198130.1 \\
\hline TLR2 & Toll-like receptor 2 & Rn02133647_s1 & NM_198769.2 \\
\hline TNF & Tumor necrosis factor & Rn00562055_m1 & NM_012675.3 \\
\hline SIGIRR & Single immunoglobulin and toll-interleukin 1 receptor (TIR) domain & Rn01501616_g1 & NM_001024887.1 \\
\hline
\end{tabular}


Table 2 Standard PCR primers

\begin{tabular}{|c|c|c|c|}
\hline Gene symbol & NCBI RefSeq & Forward primer $\left(5^{\prime}-3^{\prime}\right)$ & Reverse primer $\left(5^{\prime}\right.$ - $\left.3^{\prime}\right)$ \\
\hline Cor1 & NM_020542.2 & GTTGGGACCTTGAACCTTGA & TGTGGTTGTGGGGTAGGTTT \\
\hline $\mathrm{Ccr} 2$ & NM_021866.1 & CCAGTGTGAAGCAAATTGGA & TGGAAAATAAGGGCCACAAG \\
\hline Ccr5 & NM_053960.3 & GTCAAACGCTTCTGCAAACA & CTTGTTCCCAGCCTTCTCAG \\
\hline Cxcr2 & NM_017183.1 & CAGAGACTTGGGAGCCACTC & TCAGCAAAGTCACCAGAACG \\
\hline Cxcr3 & NM_053415.1 & AAGTTCCCAACCACAAGTGC & GGCAGGAAGGTTCTGTCAAA \\
\hline
\end{tabular}

immunofluorescence was viewed using a Zeiss laser scanning microscope (Zeiss, Oberkochen, Germany), and acquired using PASCAL software (Zeiss, v4.0).

\section{Analysis of cell death}

TUNEL labeling was used to quantify photoreceptor apoptosis in cryosections, and utilized a protocol that has been documented previously [39]. Counts were made of TUNEL positive cells in the outer nuclear layer (ONL), and were performed along the full-length of retinal sections cut in the vertical meridian (superio-inferior), including the optic disc. The final count from each animal is the average at comparable locations in two nonsequential sections.

\section{Statistical analysis}

Statistical analysis was performed using the Kruskal-Wallis one-way analysis of variance, with Dunn's multiple comparison post-test applied where desired; differences with a $P$ value $<0.05$ were considered statistically significant.

\section{Results}

Microarray analysis for chemokine-related genes following 24 hours of light damage

Analysis of microarray data compared gene expression in retinas of animals reared in dim-light conditions with those exposed to $24 \mathrm{hrs}$ of LD. The reliability of the microarray data was assessed with hierarchical clustering and principal component analysis in our previous investigation [31]; both analyses indicated high reproducibility for samples in their respective treatment conditions. From the microarray data, a list of differentially expressed chemokine-related genes $(P<0.05)$ was compiled (Table 3 ), which were grouped according to their functional roles outlined in the gene ontology consortium [34].

Chemokine ligands (GO:0008009) were the most prominent among the differentially expressed genes and included upregulation in a multitude of $\alpha(\mathrm{Ccl} 2, \mathrm{Ccl} 3, \mathrm{Ccl} 4$, Ccl7, Ccl12, Ccl20), and $\beta$ (Cxcl1, Cxcl9, Cxcl10, Cxcl11, Cxcl116) chemokines. Conversely, expression of $\mathrm{Ccl} 9$ and Cxcl6 was found to decrease following LD. Another highly represented group comprised genes involved in promoting chemokine synthesis (GO:0045080/GO:0032722), which included upregulation in Il1 $\beta$, Tnf $\alpha$, Adam17, Tlr2, and Myd88, and a decrease in Nod2. There was also an increase in expression of Sigirr, which is associated with inhibition of chemokine synthesis (GO:0045079/ GO:0032682). Expression of chemokine receptors (GO: 0019956) showed little wide modulation, although an increase in Ccr5 was observed, and the expression of Cxcr7 was reduced somewhat.

The validity of the microarray data was assessed by analyzing the expression of 12 genes from Table 3 using qPCR. These included a selection of chemokine ligands (Ccl3, Ccl4, Ccl7, Cxcl1, Cxcl10, Cxcl11) and regulators (Il1 $\beta$, Tnf $\alpha$, Adam17, Tlr2, Myd88, Sigirr). Differential expression of these genes at 24 hrs of LD, was found by PCR to be in agreement with the corresponding data obtained from the microarray (Figure 1).

\section{Relation of chemokine expression to photoreceptor cell death}

The expression of the 12 gene selections was further examined over the protracted LD time course, and contrasted with the number of TUNEL+ photoreceptors (Figure 2). The time course encompassed incremental periods during- $(1,3,6,12,17$, and 24 hrs $)$ and post-LD exposure ( 3 and 7 days).

Large increases in the number of TUNEL+ photoreceptors were observed from 12 hrs of LD onward and reached a peak at 24 hrs (Figure 2A), as reported previously [29,31]. By 3- and 7-days post-exposure, the number of TUNEL+ nuclei had decreased substantially. Expression of $\alpha(\mathrm{Ccl} 3, \mathrm{Ccl} 4, \mathrm{Ccl} 7)$, and $\beta$ (Cxcl1, Cxcl10, Cxcl11) chemokine ligands was upregulated at $12 \mathrm{hrs}$ of LD, before reaching a peak at $24 \mathrm{hrs}$ - consistent with the emergence of TUNEL+ cells (Figure 2B-C). By 3days postexposure, expression of all chemokine ligands was reduced, with only small upregulation evident by 7 days, compared to dim-reared controls. Expression of chemokine promoters Il $1 \beta$, TNF $\alpha$, Tlr2, and Myd88 and the inhibitor Sigirr exhibited similar trends in upregulation over the LD time course to the chemokine ligands (Figure $2 \mathrm{D}$ ). Il1 $\beta$ and TNF $\beta$ were the most strongly upregulated, beginning at $12 \mathrm{hrs}$ of LD; this upregulation decreased in the post exposure period, although the decreases were smaller for Tlr2 and Myd88. In contrast, 
Table 3 Differentially expressed chemokine related genes following 24 hrs LD exposure

\begin{tabular}{|c|c|c|c|}
\hline Gene title & Gene symbol & Differential expression (\%) & Affymetrix probe set ID \\
\hline \multicolumn{4}{|l|}{ Chemokine activity (GO:0008009) } \\
\hline \multirow[t]{3}{*}{ Chemokine (C-C motif) ligand 2} & $\mathrm{Ccl} 2$ & 3609.72 & 10736700 \\
\hline & & 2968.75 & 10736701 \\
\hline & & 3683.67 & 10736699 \\
\hline \multirow[t]{5}{*}{ Chemokine (C-C motif) ligand 3} & $\mathrm{Ccl3}$ & 1137.80 & 10745678 \\
\hline & & 4996.67 & 10745679 \\
\hline & & 2146.75 & 10745680 \\
\hline & & 748.47 & 10745681 \\
\hline & & 306.31 & 10745682 \\
\hline \multirow[t]{3}{*}{ Chemokine (C-C motif) ligand 4} & $\mathrm{Ccl} 4$ & 328.99 & 10736866 \\
\hline & & 247.01 & 10736865 \\
\hline & & 279.34 & 10736864 \\
\hline \multirow[t]{2}{*}{ Chemokine (C-C motif) ligand 7} & $\mathrm{Ccl7}$ & 1166.78 & 10736704 \\
\hline & & 752.47 & 10736705 \\
\hline Chemokine (C-C motif) ligand 9 & $\mathrm{Ccl} 9$ & -90.89 & 10745664 \\
\hline \multirow[t]{2}{*}{ Chemokine (C-C motif) ligand 12} & Ccl12 & 490.33 & 10736714 \\
\hline & & 393.97 & 10736715 \\
\hline Chemokine (C-C motif) ligand 20 & $\mathrm{Ccl} 20$ & 220.82 & 10924783 \\
\hline \multirow[t]{3}{*}{ Chemokine (C-X-C motif) ligand 1} & Cxcl1 & 945.55 & 10775901 \\
\hline & & 1559.57 & 10775902 \\
\hline & & 555.07 & 10775903 \\
\hline Chemokine (C-X-C motif) ligand 6 & Cxcl6 & -163.77 & 10775923 \\
\hline Chemokine (C-X-C motif) ligand 9 & Cxcl9 & 53.71 & 10771668 \\
\hline \multirow[t]{3}{*}{ Chemokine (C-X-C motif) ligand 10} & Cxcl10 & 1464.18 & 10771658 \\
\hline & & 3087.93 & 10771659 \\
\hline & & 1553.85 & 10771657 \\
\hline \multirow[t]{3}{*}{ Chemokine (C-X-C motif) ligand 11} & Cxcl11 & 271.26 & 10771652 \\
\hline & & 439.80 & 10771651 \\
\hline & & 268.55 & 10771650 \\
\hline Chemokine (C-X-C motif) ligand 16 & Cxcl16 & 145.41 & 10744462 \\
\hline \multicolumn{4}{|l|}{ Chemokine Binding (GO:0019956) } \\
\hline Chemokine (C-C motif) receptor 5 & Ccr5 & 58.98 & 10914620 \\
\hline Chemokine (C-X-C motif) receptor 7 & Cxcr7 & -60.16 & 10925293 \\
\hline \multicolumn{4}{|c|}{ Positive regulation of chemokine production (GO:0045080/GO:0032722) } \\
\hline \multirow[t]{5}{*}{ ADAM metallopeptidase domain 17} & Adam 17 & 84.01 & 10889348 \\
\hline & & 54.93 & 10889357 \\
\hline & & 124.88 & 10889340 \\
\hline & & 82.72 & 10889346 \\
\hline & & 55.11 & 10889355 \\
\hline \multirow[t]{2}{*}{ Interleukin $1 \beta$} & $\| 1 \beta$ & 210.61 & 10849843 \\
\hline & & 192.00 & 10849844 \\
\hline \multirow[t]{4}{*}{ Myeloid differentiation primary response gene 88} & Myd88 & 152.30 & 10920861 \\
\hline & & 261.01 & 10920862 \\
\hline & & 224.07 & 10920863 \\
\hline & & 144.33 & 10920866 \\
\hline
\end{tabular}


Table 3 Differentially expressed chemokine related genes following 24 hrs LD exposure (Continued)

\begin{tabular}{llll}
\hline Nucleotide-binding oligomerization domain containing 2 & Nod2 & -52.42 & 10809667 \\
Toll-like receptor $\mathbf{2}$ & Tlr2 & 123.65 & 10823972 \\
Tumor necrosis factor (TNF superfamily, member 2) & Tnfa & 106.36 & 10828025 \\
& & 119.80 & 10828023 \\
& & 111.45 & 10828024 \\
Negative regulation of chemokine production (GO:0045079/GO:0032682) & & 10726694 \\
Single immunoglobulin and toll-interleukin 1 receptor (TIR) domain $\quad$ Sigirr & 71.95 & 10726700 \\
\hline
\end{tabular}

Adam17 was upregulated over the entire time course, with a modest peak in expression at $24 \mathrm{hrs}$ of LD.

In situ localization of chemokines following light damage exposure

Chemokine ligands Ccl3, Ccl4, Ccl7, Cxcl1, and Cxcl10 were selected for further characterization in 24-hr LD retinas, by in situ hybridization (Figures 3, 4, 5, 6). No expression of chemokines was detected in retinas of dimreared animals (Figures 3, 4, 5, 6). For $\mathrm{Ccl} 3$ and $\mathrm{Ccl} 4$, mRNA staining was evident by 24 hrs of LD in irregularshaped nuclei/processes (Figure 3A-D, J-M), scattered throughout the ONL. These cells were more numerous in the superior part of the retina, which is the focal region for LD-mediated degeneration (data not shown). Counter immunolabeling for IBA1 revealed a strong co-localization

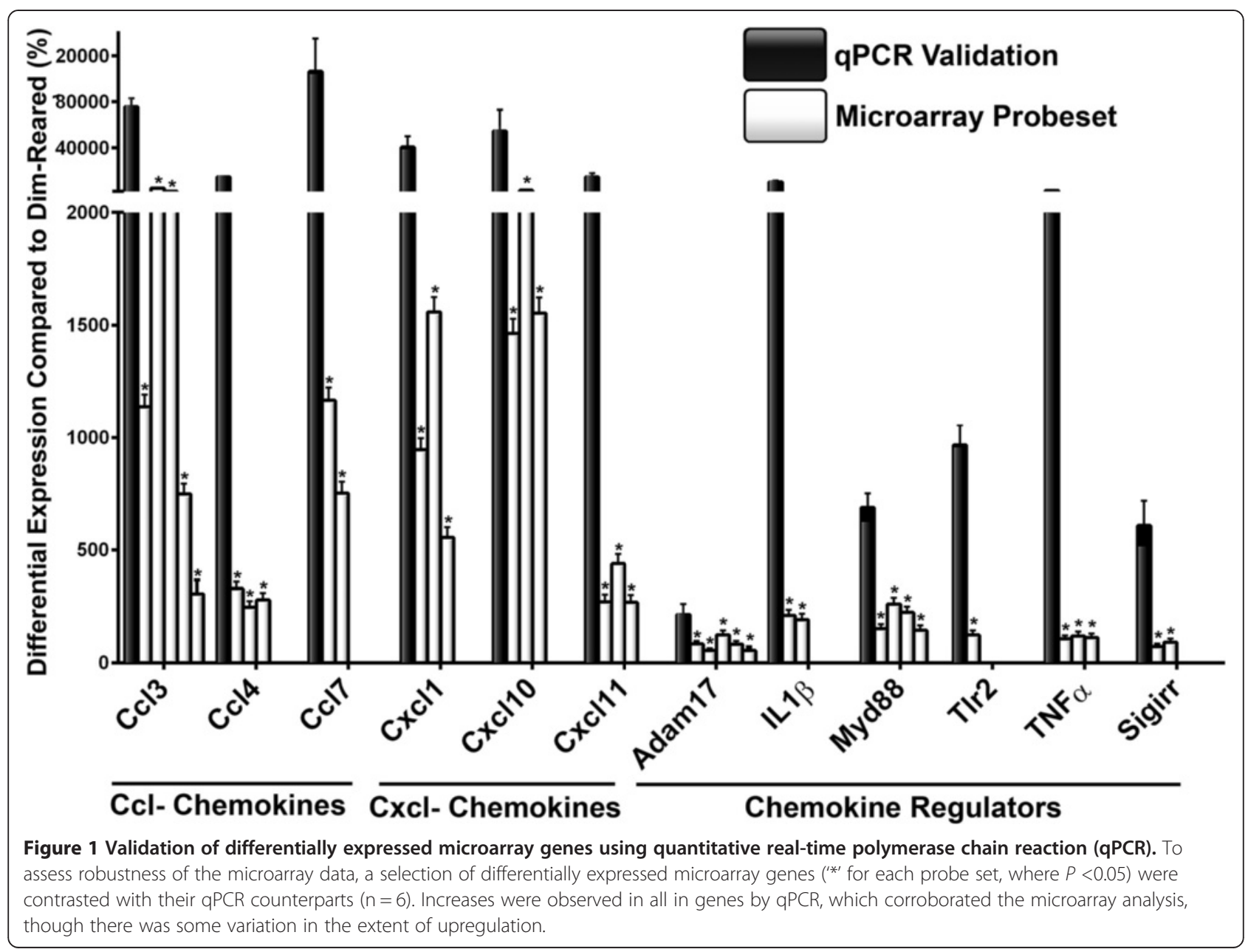



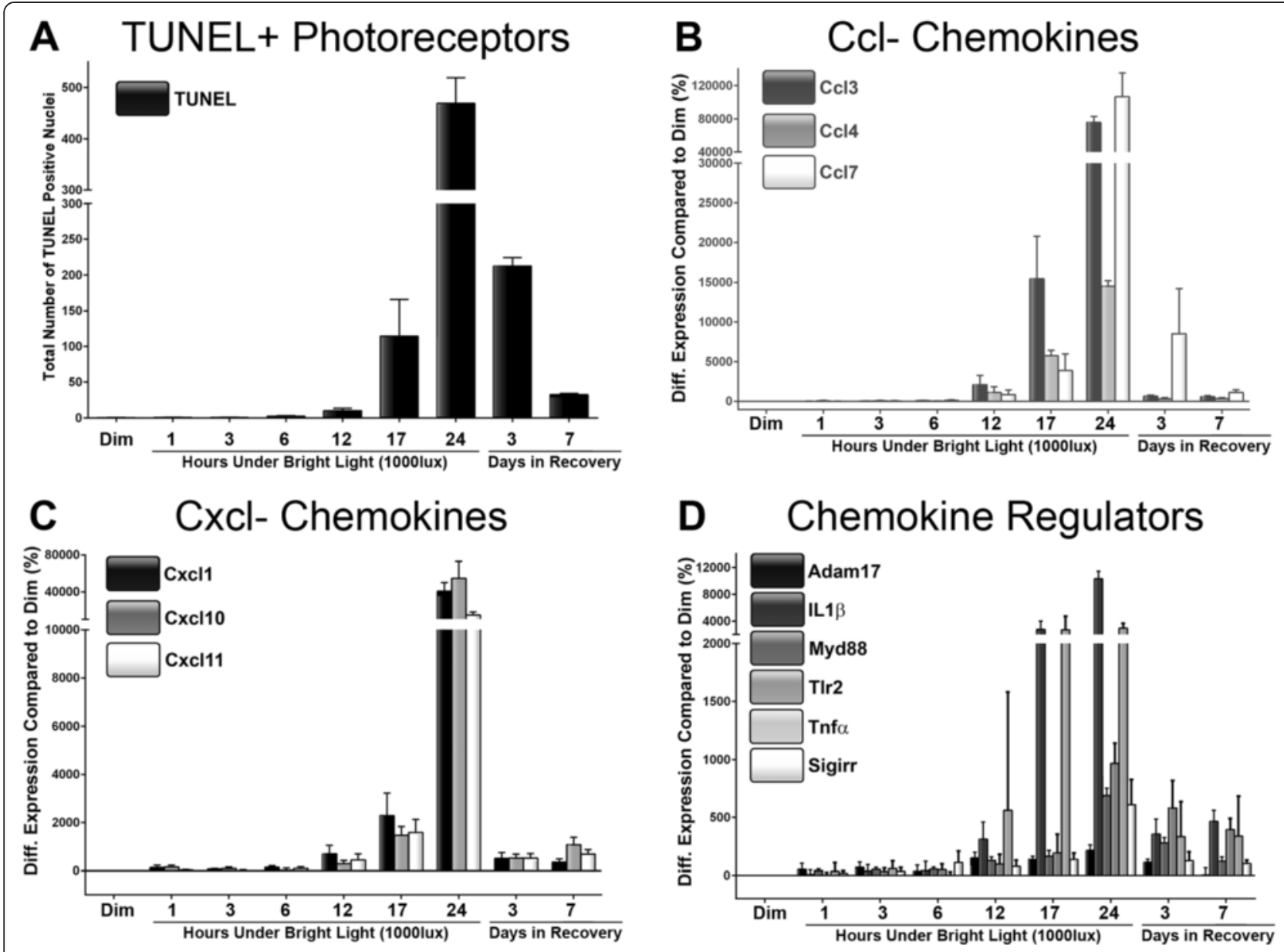

Figure 2 Expression of selected chemokines and chemokine-modulators in relation to apoptotic markers, following light damage. A: Increases in TUNEL+ photoreceptors were observed from 12 hrs light damage (LD), and peaked at 24 hrs. The number of TUNEL+ nuclei then decreased profoundly during the post exposure period. B-C: Expression of both $\mathbf{C C l}-\mathbf{( B )}$, and $\mathbf{C x C l}$ (C) ligands exhibited concurrent upregulation beginning at 12 hrs of LD, which then peaked at 24 hrs. Expression decreased sharply in all chemokines by 3-and 7-days postexposure. D: Chemokine regulators $111 \beta$, TNFa, TIr2, Myd88, and Sigirr showed emerging upregulation between 12 hrs and 24 hrs of LD, and was particularly robust in the instance $\| 1 \beta$, and TNFa. Upregulation of $\| 1 \beta$, TNFa, TIr2, Myd88, and Sigirr peaked at 24 hrs of LD and tapered off during the post-exposure period. Adam17, in contrast to the other regulators, exhibited consistent upregulation over the entire time course, with a minor peak at 24 hrs of LD. The trend in expression for all genes, as well as TUNEL, was significant by one-way ANOVA $(P<0.05) ; n=6$.

of both Ccl3 (Figure 3E-I) and Ccl4 (Figure 3N-R) with activated $\mathrm{IBA}^{+}$microglia in the ONL at 24 hrs post exposure/LD.

In situ hybridization for $\mathrm{Ccl} 7$ also evident in cells scattered throughout the ONL at $24 \mathrm{hrs}$ of LD (Figure 4B-D), but in addition was detected in cell processes radially oriented in the INL. As with the $\mathrm{Ccl} 3$ and Ccl4, this staining was more frequent in the superior retina (data not shown). Counter immunolabeling for IBA1 indicated that staining for $\mathrm{Ccl} 7$ in the ONL coincided with activated microglial cells (Figure 4H-K). In the INL, Ccl7 mRNA labeling of cell processes was IBA1-negative (Figure 4O-P). Instead, these cells co-localized Ccl7 mRNA with immunoreactivity for vimentin (Figure 4L-N), consistent with an identification of Müller cell processes.
The localizations of Cxcl1 and Cxcl10 resembled each other (Figures 5 and 6). Following 24 hrs of LD, Cxcl1 (Figure 5B-C) and Cxcl10 (Figure 6B-C) mRNA was labeled in putative RPE cells, predominately in the superior retina (Figures 5D, 6D). The identity of these Cxcl1/Cxcl10 expressing cells was confirmed by positive counter immunolabeling for RPE65 (Figures 5I-K, 6I-K). Cxcl1 and Cxcl10 mRNA labeling was also detected in radial processes within the INL, mainly in the superior retina, at $24 \mathrm{hrs}$ of LD (Figures 5E, 6E). In this location, Cxcl1 and Cxcl10 mRNA labeling colocalized strongly with vimentin immunoreactivity consistent with an identification of Müller cell processes. (Figures 5G-H, 6G-H). A summary of these data is provided in Table 4. 


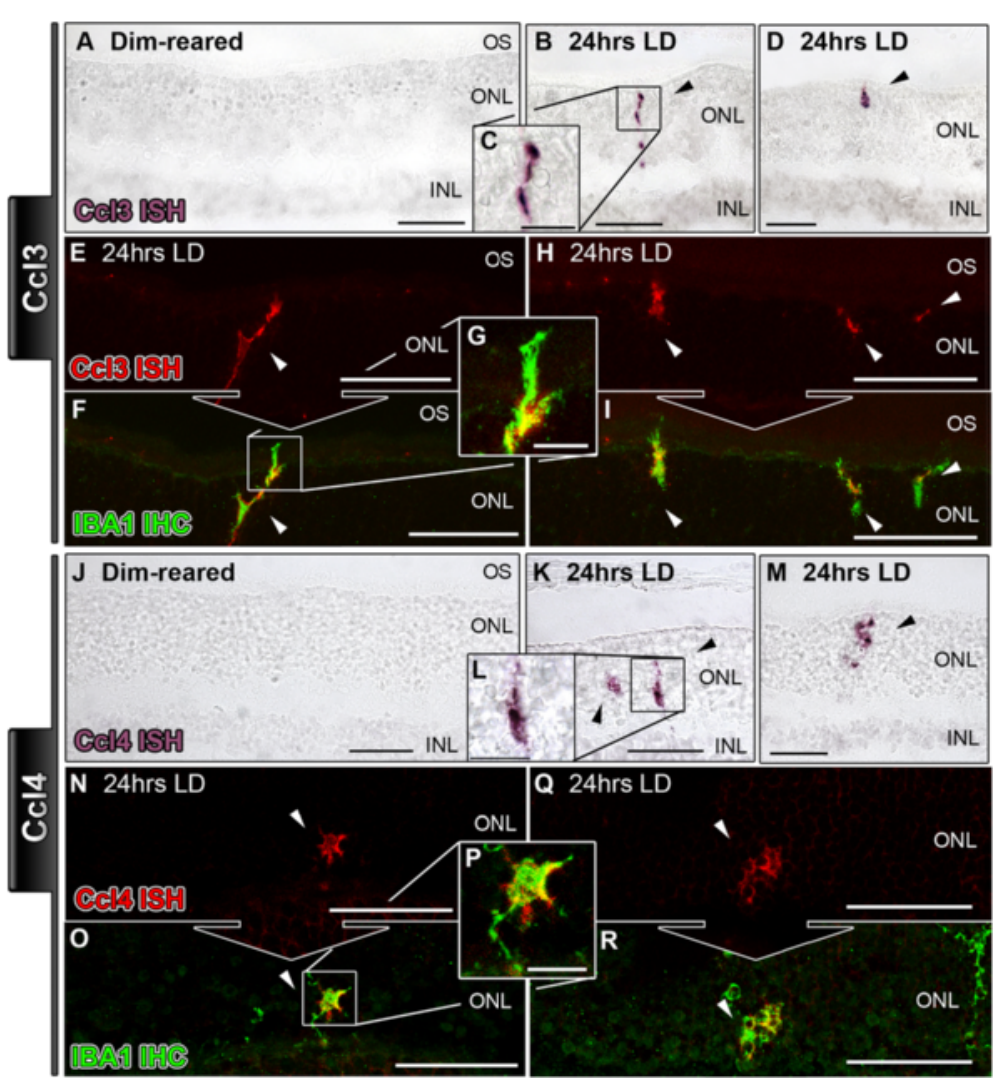

Figure $\mathbf{3}$ In situ hybridization for $\mathrm{Ccl} 3$ and $\mathrm{Ccl} 4$ mRNA in the retina following exposure to $\mathbf{2 4}$ hours of light damage. In situ hybridization for $\mathrm{CCl} 3$ is documented in A-I, while CCl4 is shown in J-R. A: In retinas from dim-reared animals, staining for Ccl3 was not observed in the retina. B-D: After 24 hrs light damage (LD), there was staining for $\mathrm{CCl} 3$ in irregularly shaped nuclei - ranging from elongated to globular - traversing the outer nuclear layer (ONL) of the superior retina (arrowheads). Conversely, few Cc3-expressing cells were found in the inferior retina (data not shown). E-I: Nuclei stained for Ccl3 mRNA (red) showed strong correlation (arrowheads) to activated microglia, which were counterimmunolabeled with an antibody to IBA1 (green). J: Ccl4 mRNA staining was not apparent in sections of dim-reared retinas. J-M: At 24 hrs, LD staining for Ccl4 was detected among clusters of irregular nuclei in the ONL from the superior retina (arrowheads); little-to-none were observed in the inferior retina (data not shown). N-R: CCl4-expressing nuclei (red) in retinal sections show strong immunofluorescence (arrowheads) for IBA1+ microglia (green), much like Ccl3 (E-I). INL, inner nuclear layer; IHC, immunohistochemistry; ISH, in situ hybridization; ONL, outer nuclear layer; OS, outer segments.

\section{Recruitment of $\mathrm{CD} 45^{+}$and expression of chemokine receptors}

Changes in the number of $\mathrm{CD} 45^{+}$monocytes/microglia following LD were identified using FACS; representative gating strategies and scatter blots are noted in Figure 7A. In dim-reared retinas, $\mathrm{CD} 45^{+}$cells comprised a relatively small population of the gated retinal isolates, at approximately $0.098 \%$ (Figure 7B). After $24 \mathrm{hrs}$ of LD, the retinal CD45+ population rose substantially to $0.340 \%(P<0.05)$, then reaching $0.875 \%$ by 3 days $(P<0.05)$. A further increase to $1.24 \%$ was observed at 7 days, although this was not significantly different from the population size at 3 days $(P>0.05)$.

PCR of RNA from the CD45-FACS isolates at each time point showed differential expression of the chemokine receptors Ccr1, Ccr2, Ccr5, Cxc2, and Cxcr3 (Figure 7), which are known to bind the differentially expressed ligands validated by qPCR in Figure 1 [40]. CD45 isolates express all chemokine receptors assessed (Figure 7C-G), although the density of the PCR bands varies depending on the time point. Ccr1, Ccr2, Ccr5, and Cxcr2 appear to be lowly expressed in dim-reared animals and more highly expressed following $24 \mathrm{hrs}$ of $\mathrm{LD}$ and at the post-exposure time points (Figure 7C-F). Cxcr3 showed no amplification in dim-reared samples, was highly expressed at $24 \mathrm{hrs}$ of LD, and was low by 7-days post-exposure (Figure 7F).

\section{Discussion}

These findings identify a complex network of chemokine activity elicited by light-induced retinal degeneration and include several novel findings. First, we show that a suite of $\alpha(\mathrm{Ccl} 3, \mathrm{Ccl} 4, \mathrm{Ccl} 7)$ and $\beta$ (Cxcl1, Cxcl10, Cxcl11) chemokines are upregulated following $24 \mathrm{hrs}$ of LD, and these chemokines correlate strongly with the emergence of photoreceptor death and upregulation of chemokine regulatory genes (Il1 $\beta$, Tnfo, Tlr2, Myd88, Adam17, Sigirr). 


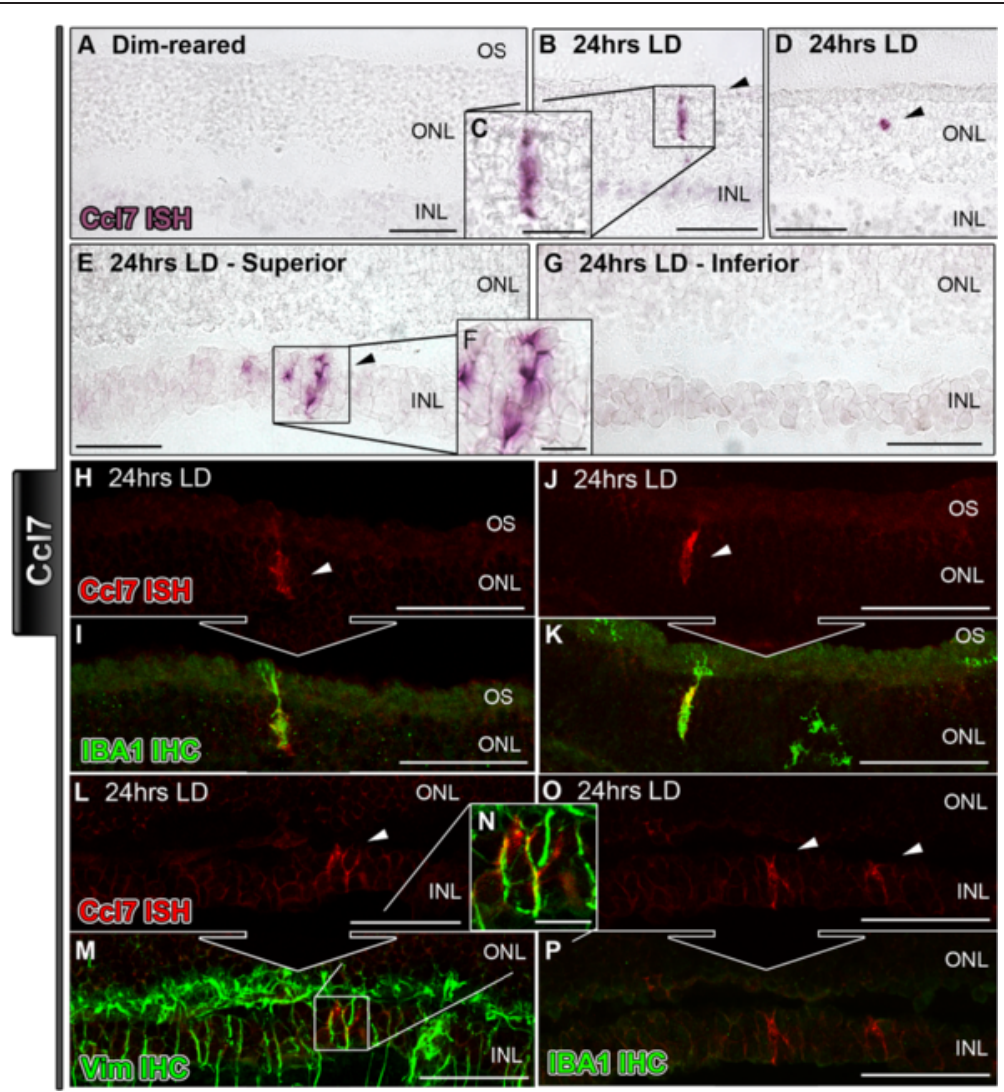

Figure 4 In situ hybridization for Ccl7 mRNA in the retina following exposure to $\mathbf{2 4}$ hours of light damage. A: Staining for Ccl7 was not observed in the retinas of dim-reared animals B-D: In retinas exposed to 24 hrs light damage (LD), CCl7 expression was found in infrequent clusters of nuclei within the outer nuclear layer (ONL) of the superior retina (arrowheads), with few in the inferior (data not shown). E-F: Ccl7 expression was also apparent in radial processes (arrowhead) dispersed within inner nuclear layer (INL) of the superior retina, following 24 hrs of LD. G: Ccl7 staining was less evident in the inferior portion of the retina following LD. H-K: Ccl7-stained nuclei (red) in the ONL were found to coincide with activated IBA1-immunolabeled microglia (green; arrowheads). L-N: Staining for Ccl7 mRNA (red) in the INL showed strong co-localization for vimentin-immunreactive Müller cell processes (arrowheads). O-P: Ccl7-expressing cells in the INL (red; arrowheads) were negative for IBA1 immunostaining. INL, inner nuclear layer; IHC, immunohistochemistry; ISH, in situ hybridization; ONL, outer nuclear layer; OS, outer segments.

Second, in situ hybridization demonstrates that Müller cells, RPE, and activated microglia comprise a 'trio' of cells that express select chemokine ligands $(\mathrm{Ccl} 3, \mathrm{Ccl} 4, \mathrm{Ccl} 7$, Cxcl1, Cxcll0) after LD. Third, we show that LD-induced upregulation of chemokines is proceeded by infiltration of $\mathrm{CD}_{4} 5^{+}$monocytes/microglia, which bear corresponding receptors (Ccr1, Ccr2, Ccr5, Cxcr2, Cxcr3) at 3-days postexposure.

Several investigations have previously identified upregulation in chemokine ligands following retinal light damage, including Ccl2, Ccl3, Ccl4, Ccl7, Cxcl1, and Cxcl10 through PCR and microarray analysis [35,41-43]. However, these studies did not identify the source of their expression in the retinal environment in situ, nor did they closely relate chemokine expression to photoreceptor cell death and regulatory factor expression. To our knowledge, this is the first investigation to demonstrate a preferential localization of chemokine mRNA in activated microglia $(\mathrm{Ccl} 3, \mathrm{Ccl} 4$,
Ccl7), Müller cells (Ccl7, Cxcl1, Cxcl10), and RPE (Cxcl1, Cxcl10) in the degenerating retina. These observations are supported by a number of in vitro studies, which have reported expression of Ccl3 by microglia [43], and Cxcl1 [44-46] and Cxcl10 [47,48] in Müller cells or RPE in response to various stimuli including cytokines and bacterial pathogens. The expression profiles of chemokine ligands by microglia, Müller cells, and RPE following LD were highly defined and cell-specific. The precise roles of these discrete chemokine phenotypes in the degenerating retina are unclear, despite a bourgeoning understanding of chemokine activity in recent years. Functional significance may be inferred, however, based on current understanding of the chemokines identified.

\section{Chemokine secretion by activated microglia}

We find that $\mathrm{Ccl} 3, \mathrm{Ccl} 4$, and $\mathrm{Ccl} 7$ are expressed by activated microglia after LD. Previous in vitro and in vivo 


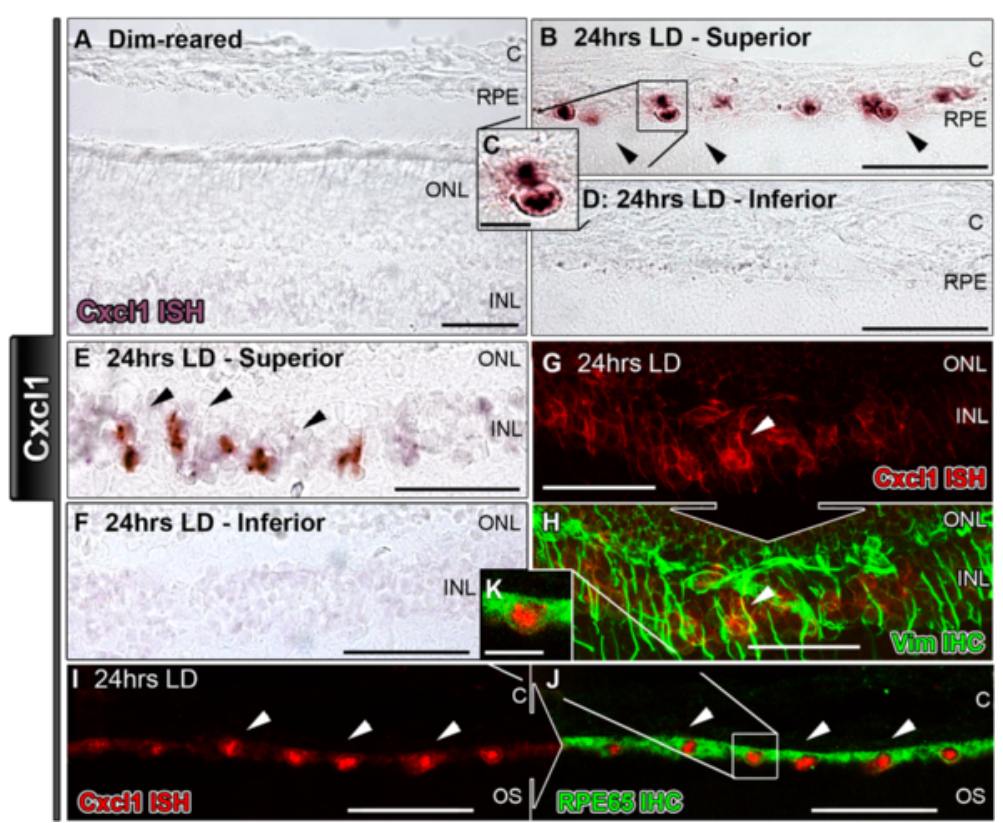

Figure $\mathbf{5}$ In situ hybridization for Cxcl1 mRNA in the retina following exposure to $\mathbf{2 4}$ hours of light damage. A: In sections from dim-reared animals, staining for Cxcl1 was absent. B-D: Retinas exposed to 24 hrs of LD showed staining for Cxcl1 in putative retinal pigment epithelium (RPE) cells (arrowheads) in the superior retina (B-C), and few-to-none in the inferior (D). E-F: Staining for Cxcl1 mRNA was also present in the inner nuclear layer (INL) of superior retina following 24 hrs of LD (E; arrowheads), and mostly absent in inferior retina (F). G-H: Retinas with stain for Cxcl1 mRNA in the INL (red; arrowhead), which was found to co-localize with vimentin-immunolabeled Müller cell processes (green; arrowheads). I-J: Localized Cxcl1 stain in putative RPE cells (red; arrowheads) correlated strongly with immunolabeling for RPE65 (green; arrowheads); Cxcl1 stain appeared to be localized in the nucleus, rather than cytoplasm. C, choroid; INL, inner nuclear layer; IHC, immunohistochemistry; ISH, in situ hybridization ONL, outer nuclear layer; OS, outer segments.

studies indicate that Ccl3 is involved in the proliferation and mobilization of mature myeloid progenitor cells, as well as in recruitment of bone marrow-derived monocytes [49-52]. This function may be exerted through the binding of receptor Ccr1 [53,54], although Ccl3 also interacts with $\mathrm{Ccr} 5$, which mediates monocyte recruitment, and mobilization of Th1 T cells $[52,55,56]$. In the retina, deficiencies in $\mathrm{Ccl} 3$ reduce progressive photoreceptor death and monocyte recruitment in degenerative $\mathrm{Abca}^{-/-} \mathrm{Rdh}^{-/-}$mice, and in the $\mathrm{Mertk}^{-/-}$mouse model of retinitis pigmentosa [43]. Ccl4 also interacts with Ccr5, to promote recruitment of monocytes into the retina when subjected to oxygen induced retinopathy [57].

In contrast, $\mathrm{Ccl} 7$ is a ligand of the better documented receptor $\mathrm{Ccr} 2$, and is major determinant in chemotaxis of monocytes. Deficiencies in Ccr2 impair monocyte recruitment to tissues in disease models ranging from arthrosclerosis [58] and autoimmune encephalitis [59], to choroidal neovascularization [26]. Several studies indicate that $\mathrm{Ccl} 2$ and $\mathrm{Ccl} 7$ are the primary agonists of Ccr2, in which ablation of either of these ligands reduced monocyte recruitment from bone marrow to peripheral vessels in thioglycollate-induced peritonitis [60] and Listeria monocytogenes infection [61]. Taken together, the findings suggest that activated 'resident' microglia are potent drivers of monocyte filtration from the vasculature to the parenchyma following LD. The present results suggest that this activity is mediated, at least in part, by activated microglia through the expression of specific chemokines. This expression is possibly triggered by migrating microglia that encounter stressed photoreceptors in the ONL. This suggestion is supported by our findings that recruited $\mathrm{CD} 45^{+}$cells bear the corresponding Ccr1, Ccr2, and Ccr5 receptors following LD and found to be expressed by monocytes and macrophages in other studies $[56,62,63]$.

\section{Chemokine secretion by retinal pigment epithelium and Müller cells}

In contrast to the monocyte-centric chemotactic profile of activated microglia, chemokine expression by Müller cells and RPE suggests they have a broader role in modulation of the leukocyte response. Müller cells and RPE shared a similar expression profile of upregulation of Cxcl1 and Cxcl10 following LD, while Müller cells also expressed Ccl7. We have shown previously that Müller cells also express Ccl2 following LD [29].

Cxcl1, and its cognate receptor Cxcr2, are commonly associated with recruitment of neutrophils from the vascular supplies [64-66], and signaling via this receptor is 


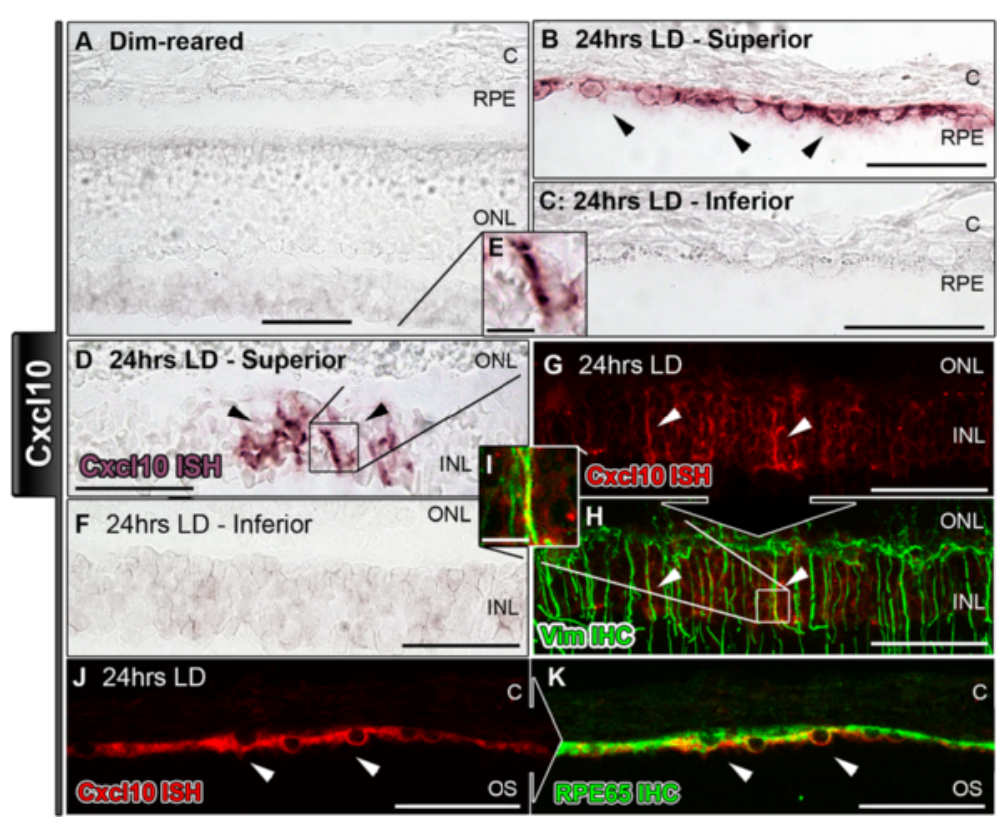

Figure 6 In situ hybridization for Cxcl10 mRNA in the retina following exposure to 24 hours of light damage. A: Expression of Cxcl10 was not apparent in dim-reared sections. B-C: Sections from the superior retina (B) showed stain for Cxcl10 mRNA in putative retinal pigment epithelium (RPE) cells (arrowheads) following 24 hrs light damage (LD), while no staining was observed in the inferior retina (D). D-E: Following 24 hrs of LD, stain for Cxcl10 mRNA appeared in the INL within superior retina (D-E; arrowheads). F: Staining for Cxcl10 was not readily apparent in the inferior retina. G-I: Sections with labeling for Cxcl10 mRNA (red; arrowheads) in the INL, which correlated with Müller cells immunolabeled with vimentin (green; arrowheads). J-K: Putative RPE cells, which were positive for Cxcl10 mRNA labeling (red; arrowheads), were also immunoreactive for the marker RPE65 (green; arrowheads). C, choroid; INL, inner nuclear layer; IHC, immunohistochemistry; ISH, in situ hybridization ONL, outer nuclear layer; OS, outer segments.

implicated in the pathogenesis of rheumatoid arthritis [67,68], lung injury [69], and adenoviral keratitis [70]. Furthermore, neutrophil recruitment contributes to pathology in choroidal neovascularization [71] and in loss of blood retinal barrier integrity in RPE-choroid explants [72]. Cxcl1 and Cxcr2 are also implicated in mobilization of monocytes, in models of atherosclerosis $[73,74]$ and is Cxcr2 expressed by CNS- and retinal-derived monocytes [75,76].

On the other hand, Cxcl10 plays a role in chemotaxis of T cells via Cxcr3 signaling. Cxcr3 signaling is required for recruitment of cytotoxic $\mathrm{T}$ cells in West Nile virus encephalitis [77,78], and in the eye, Cxcl10 mediates $\mathrm{Th} 1 \mathrm{~T}$ cell trafficking in response to chronic ocular

Table 4 Summary of retinal $\mathrm{Ccl}$ and $\mathrm{Cxcl}$ localization following light damage

\begin{tabular}{llll}
\hline Gene & Müller cells & IBA1+ microglia & Retinal pigment epithelium \\
\hline $\mathrm{CCl} 3$ & - & + & - \\
$\mathrm{CCl} 4$ & - & + & - \\
$\mathrm{CCl} 7++$ & + & - \\
$\mathrm{CxCl}+$ & - & + \\
$\mathrm{CxCl} 10+$ & - & + \\
\hline
\end{tabular}

Toxoplasmosis [79]. Besides T cells, Cxcr3 is also expressed on monocytes/microglia as described in vitro and in vivo [80-82] and may modulate their recruitment in response to noxious stimuli. Supplementation with Cxcl10 also promotes the survival of photoreceptor in vitro and in retinal explants, which suggest additional neurotrophic properties [48]. Neutrophil and $\mathrm{T}$ cell activity are poorly characterized in lightinduced retinal degeneration, possibly because, in instances where it has been investigated, their numbers are relatively small compared monocytes/microglia [43]. Therefore, the precise recruitment and function of neutrophils and $\mathrm{T}$ cells in retinal light damage warrants further investigation.

Synthesis of Cxcl1 and Cxcl10 by RPE and Müller cells and their juxtaposition to the choriocapillaris and retinal vasculature, respectively, possibly reflects their role as efficient mediators of chemotaxis of monocytes, neutrophils, and $\mathrm{T}$ cells from the circulation. The additional secretion of Ccl7 by Müller cells - in conjunction with Ccl2 [29] - may suggest a stronger emphasis on monocyte recruitment from the retinal vessels following LD, consistent with observation of an influx of bone marrow-derived monocytes from the retinal vasculature in retinal injury following exposure to bright light [83]. 

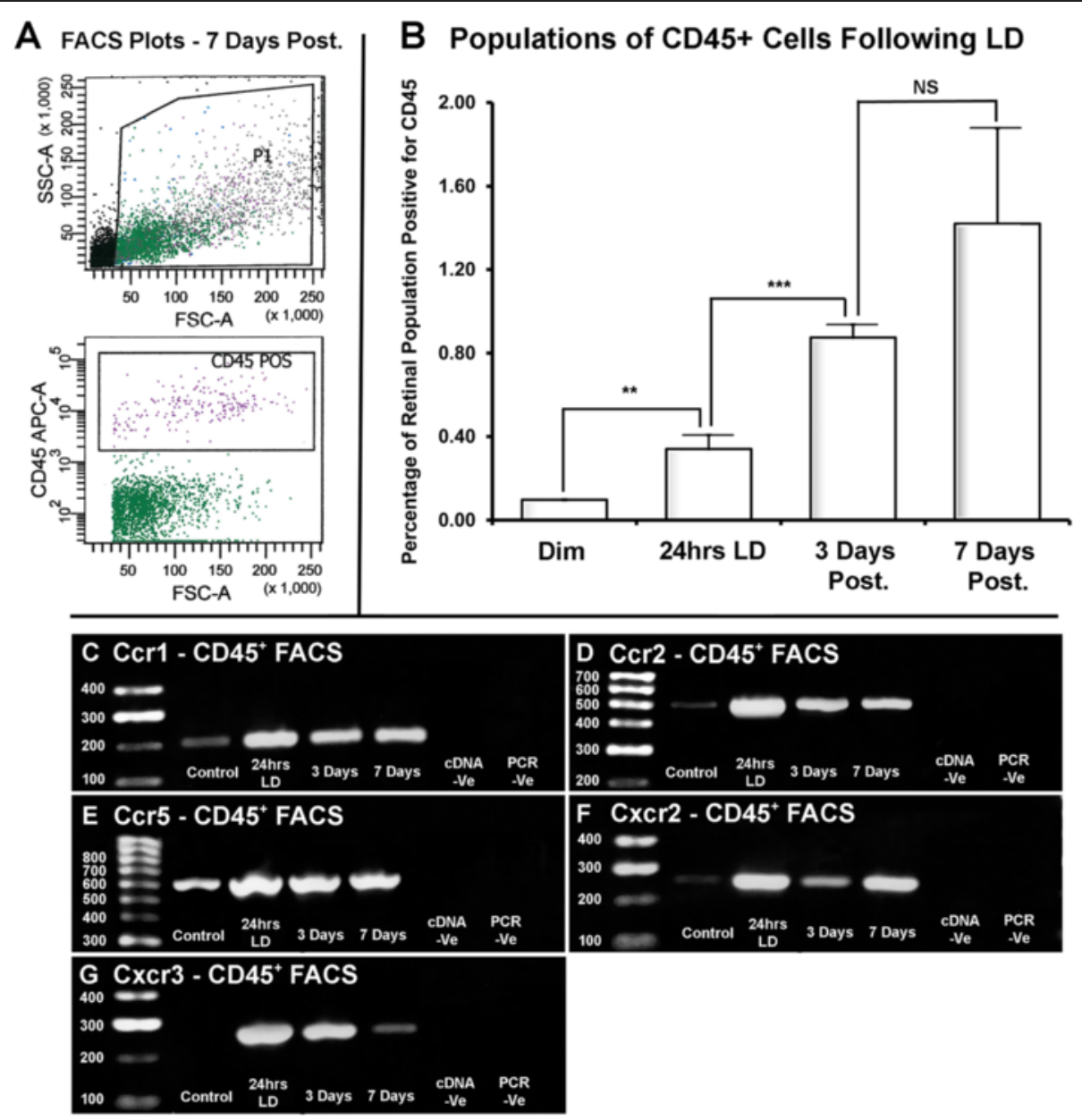

Figure 7 Changes the number of $\mathrm{CD}^{4} 5^{+}$cells using fluorescence activated cell sorting (FACS), and their expression of chemokine receptors. A: Representative FACS plots, with gating strategies, for a 7-days postexposure sample stained for CD45. Gating methodology was applied equally for all samples. B: Histogram depicts changes in the population of retinal $C D 45^{+}$cells following light damage (LD). Proportion of CD45 cells roughly tripled following 24 hrs of $L D(P<0.05)$, and continued to increase substantially during the post-exposure period after 3 days $(P<0.05)$; a further increase at 7 days was not significant $(P>0.05)$. The overall trend was significant by one-way ANOVA $(P<0.05) ; n=5$. C-G: Representative images of PCR products via electrophoresis for $\mathrm{Ccr} 1, \mathrm{Ccr} 2, \mathrm{Ccr} 5, \mathrm{Cxcr2}, \mathrm{Cxcr3}$, in samples of CD45-sorted cells. Receptor expression was low in dim-reared control samples (C-F), and absent for Cxcr3 (G). Expression increased substantially following 24 hrs of LD for every receptor assessed (C-G), and was maintained through the post exposure period, with the exception of $\mathrm{Cxcr3}$ (G).

Factors that promote chemokine expression in the degenerating retina

We also find in this study the upregulation of factors that have broad modulatory roles in chemokine secretion, including the pro-inflammatory cytokines IL1 $\beta$ and TNF $\alpha$. These factors induce expression of both $\alpha$ and $\beta$ chemokines in vitro [84] and under various conditions including mycobacterial infection [85], nephrotoxicity [86], LPS-induced endotoxemia [87], and arthritis [88]. Other genes identified in this study that may induce chemokine expression are Tlr2 [89,90] and Myd88 [91,92].

The events leading to collective synthesis of chemokines by microglia, Müller cells and RPE following LD are uncertain, although recent evidence conducted in vitro points to an interactive role with microglia in chemokine secretion. Müller cells co-cultured with LPSactivated microglia were found to upregulate expression of $\mathrm{Ccl} 2$ and $\mathrm{Ccl} 3$ [93]. These microglia-stimulated Müller cells in turn induced reciprocal activation of unstimulated microglial cultures, including upregulation of Il1 $\beta$. Co-culturing with activated microglia also induced upregulation chemokines in RPE cultures, such as $\mathrm{Ccl} 2$ and $\mathrm{Ccl} 5$ [94]. The data suggest that the trio of cells identified as expressing chemokines in the LD model co-activate; whether direct interaction between cell types is required is unclear, although, if so, would be most likely mediated by activated microglia, which are the only motile cell of the trio. It should be noted that in vivo Müller cells and RPE do not express $\mathrm{Ccl} 3$ and $\mathrm{Ccl} 2$, respectively. 


\section{Conclusions}

The study shows that microglia, Müller cells, and RPE each contribute to the trafficking of leukocytes following retinal damage through coordinated chemokine secretion. We show that chemokine expression by this trio of cells precedes mass recruitment of $\mathrm{CD} 45^{+}$cells, which bear the corresponding chemokine receptors and which increased in number in the retina over the time course of the experiment. Our findings provide valuable insight into chemokine activity in retinal degenerations.

\begin{abstract}
Abbreviations
Adam17: ADAM metallopeptidase domain 17; AEEC: Animal Experimentation Ethics Committee; AMD: age-related macular degeneration; C: choroid; Ccl12: Chemokine (C-C motif) ligand 12; $\mathrm{Cl} 2$ : Chemokine ( $\mathrm{C}-\mathrm{C}$ motif) ligand 2; Ccl20: Chemokine (C-C motif) ligand 20; $\mathrm{Cl} 3$ : Chemokine (C-C motif) ligand 3; Ccl4: Chemokine (C-C motif) ligand 4; Ccl7: Chemokine (C-C motif) ligand 7; Ccl9: Chemokine (C-C motif) ligand 9; Ccr5: Chemokine (C-C motif) receptor 5; CNS: central nervous system; Cxcl1: Chemokine (C-X-C motif) ligand 1; Cxcl10: Chemokine (C-X-C motif) ligand 10; CxCl11: Chemokine (C-X-C motif) ligand 11; Cxcl16: Chemokine (C-X-C motif) ligand 16; Cxcl6: Chemokine (C-X-C motif) ligand 6; Cxcl9: Chemokine (C-X-C motif) ligand 9; Cxcr7: Chemokine (C-X-C motif) receptor 7; FACS: fluorescence activated cell sorting; GAPDH: glyceraldehyde-3-phosphate dehydrogenase; HBSS: Hank's balanced salt solution; IHC: immunohistochemistry; II $\beta$ : Interleukin 13; INL: inner nuclear layer; ISH: in situ hybridization; LD: light damage; Myd88: Myeloid differentiation primary response gene 88; Nod2: Nucleotidebinding oligomerization domain containing 2; ONL: outer nuclear layer; OS: outer segments; PCR: polymerase chain reaction; qPCR: quantitative realtime polymerase chain reaction; RPE: retinal pigment epithelium; SD: Sprague-Dawley; TIr2: Toll-like receptor 2; Tnfa: Tumor necrosis factor (TNF superfamily, member 2); TUNEL: terminal deoxynucleotidyl transferase dUTP nick-end labeling.
\end{abstract}

\section{Competing interests}

The authors declare that they have no competing interests.

\section{Authors' contributions}

MVR designed the experiments, conducted the experiments, conducted the analysis, and wrote the paper; RCN designed the experiments and conducted the experiments; RXC conducted the experiments and conducted the analysis; KV designed the experiments; and JMP designed the experiments and wrote the paper. All contributing authors have read and approved the final version of the manuscript.

\section{Received: 9 October 2014 Accepted: 18 December 2014}

Published online: 17 January 2015

\section{References}

1. Ransohoff RM. Chemokines and chemokine receptors: standing at the crossroads of immunobiology and neurobiology. Immunity. 2009;31:711-21.

2. Bajetto A, Bonavia R, Barbero S, Schettini G. Characterization of chemokines and their receptors in the central nervous system: physiopathological implications. J Neurochem. 2002;82:1311-29.

3. Zlotnik A, Yoshie O. Chemokines: a new classification system and their role in immunity. Immunity. 2000;12:121-7.

4. Ezzat MK, Hann CR, Vuk-Pavlovic S, Pulido JS. Immune cells in the human choroid. Br J Ophthalmol. 2008;92:976-80.

5. Gupta N, Brown KE, Milam AH. Activated microglia in human retinitis pigmentosa, late-onset retinal degeneration, and age-related macular degeneration. Exp Eye Res. 2003;76:463-71.

6. Penfold PL, Killingsworth MC, Sarks SH. Senile macular degeneration. The involvement of giant cells in atrophy of the retinal pigment epithelium. Invest Ophthalmol Vis Sci. 1986;27:364-71.

7. Cherepanoff S, McMenamin P, Gillies MC, Kettle E, Sarks SH. Bruch's membrane and choroidal macrophages in early and advanced age-related macular degeneration. Br J Ophthalmol. 2009;94:918-25.
8. Lewis GP, Sethi CS, Carter KM, Charteris DG, Fisher SK. Microglial cell activation following retinal detachment: a comparison between species. Mol Vis. 2005;11:491-500

9. Nakazawa T, Hisatomi T, Nakazawa C, Noda K, Maruyama K, She H, et al. Monocyte chemoattractant protein 1 mediates retinal detachment-induced photoreceptor apoptosis. Proc Natl Acad Sci U S A. 2007;104:2425-30.

10. Vrabec F. Activated human retinal microglia under pathological conditions. Albrecht Von Graefes Arch Klin Exp Ophthalmol. 1975;196:49-60.

11. Yuan L, Neufeld AH. Activated microglia in the human glaucomatous optic nerve head. J Neurosci Res. 2001;64:523-32.

12. Neufeld AH. Microglia in the optic nerve head and the region of parapapillary chorioretinal atrophy in glaucoma. Arch Ophthalmol. 1999;117:1050-6.

13. Zeng HY, Green WR, Tso MO. Microglial activation in human diabetic retinopathy. Arch Ophthalmol. 2008;126:227-32.

14. Kataoka K, Nishiguchi KM, Kaneko H, van Rooijen N, Kachi S, Terasaki H. The roles of vitreal macrophages and circulating leukocytes in retinal neovascularization. Invest Ophthalmol Vis Sci. 2011;52:1431-8.

15. Ni YQ, Xu GZ, Hu WZ, Shi L, Qin YW, Da CD. Neuroprotective effects of naloxone against light-induced photoreceptor degeneration through inhibiting retinal microglial activation. Invest Ophthalmol Vis Sci. 2008:49:2589-98.

16. Chang $\mathrm{CJ}$, Cherng $\mathrm{CH}$, Liou WS, Liao CL. Minocycline partially inhibits caspase-3 activation and photoreceptor degeneration after photic injury. Ophthalmic Res. 2005;37:202-13.

17. Yang LP, Zhu XA, Tso MO. A possible mechanism of microglia-photoreceptor crosstalk. Mol Vis. 2007;13:2048-57.

18. Ibrahim AS, El-Shishtawy MM, Pena Jr A, Liou Gl. Genistein attenuates retinal inflammation associated with diabetes by targeting of microglial activation. Mol Vis. 2010;16:2033-42.

19. Krady JK, Basu A, Allen CM, Xu Y, LaNoue KF, Gardner TW, et al. Minocycline reduces proinflammatory cytokine expression, microglial activation, and caspase- 3 activation in a rodent model of diabetic retinopathy. Diabetes. 2005:54:1559-65.

20. Bosco A, Inman DM, Steele MR, Wu G, Soto I, Marsh-Armstrong N, et al. Reduced retina microglial activation and improved optic nerve integrity with minocycline treatment in the DBA/2 J mouse model of glaucoma. Invest Ophthalmol Vis Sci. 2008:49:1437-46.

21. Neufeld AH. Pharmacologic neuroprotection with an inhibitor of nitric oxide synthase for the treatment of glaucoma. Brain Res Bull. 2004;62:455-9.

22. Luster AD. Chemokines-chemotactic cytokines that mediate inflammation. N Engl J Med. 1998:338:436-45.

23. Oppenheim JJ, Zachariae CO, Mukaida N, Matsushima K. Properties of the novel proinflammatory supergene "intercrine" cytokine family. Annu Rev Immunol. 1991:9:617-48.

24. Ransohoff RM, Glabinski A, Tani M. Chemokines in immune-mediated inflammation of the central nervous system. Cytokine Growth Factor Rev. 1996;7:35-46.

25. Newman AM, Gallo NB, Hancox LS, Miller NJ, Radeke CM, Maloney MA, et al. Systems-level analysis of age-related macular degeneration reveals global biomarkers and phenotype-specific functional networks. Genome Med. 2012;4:16.

26. Tsutsumi C, Sonoda KH, Egashira K, Qiao H, Hisatomi T, Nakao S, et al. The critical role of ocular-infiltrating macrophages in the development of choroidal neovascularization. J Leukoc Biol. 2003;74:25-32.

27. Luhmann UF, Robbie S, Munro PM, Barker SE, Duran Y, Luong V, et al. The drusenlike phenotype in aging Ccl2-knockout mice is caused by an accelerated accumulation of swollen autofluorescent subretinal macrophages. Invest Ophthalmol Vis Sci. 2009;50:5934-43.

28. Sennlaub F, Auvynet C, Calippe B, Lavalette S, Poupel L, Hu SJ, et al. CCR2(+) monocytes infiltrate atrophic lesions in age-related macular disease and mediate photoreceptor degeneration in experimental subretinal inflammation in $\mathrm{Cx3}$ cr1 deficient mice. EMBO Mol Med. 2013;5:1775-93.

29. Rutar M, Natoli R, Valter K, Provis JM. Early focal expression of the chemokine $\mathrm{C} \mathrm{C} 2$ by Müller cells during exposure to damage-inducing bright continuous light. Invest Ophthalmol Vis Sci. 2011;52(5):2379-88.

30. Rutar MV, Natoli RC, Provis JM. Small interfering RNA-mediated suppression of C $\mathrm{Cl} 2$ in Muller cells attenuates microglial recruitment and photoreceptor death following retinal degeneration. J Neuroinflammation. 2012;9:221.

31. Rutar M, Natoli R, Valter K, Provis JM. Analysis of complement expression in light-induced retinal degeneration: Synthesis and deposition of C3 by 
microglia/macrophages is associated with focal photoreceptor degeneration. Invest Ophthalmol Vis Sci. 2011;52(8):5347-58.

32. Ma W, Cojocaru R, Gotoh N, Gieser L, Villasmil R, Cogliati T, et al. Gene expression changes in aging retinal microglia: relationship to microglial support functions and regulation of activation. Neurobiol Aging. 2013;34:2310-21

33. Natoli R, Provis J, Valter K, Stone J. Gene regulation induced in the C57BL/6 J mouse retina by hyperoxia: a temporal microarray study. Mol Vis. 2008;14:1983-94

34. Ashburner M, Ball CA, Blake JA, Botstein D, Butler H, Cherry JM, et al. Gene ontology: tool for the unification of biology. The Gene Ontology Consortium. Nat Genet. 2000;25:25-9.

35. Chen L, Wu W, Dentchev T, Zeng Y, Wang J, Tsui I, et al. Light damage induced changes in mouse retinal gene expression. Exp Eye Res. 2004;79:239-47.

36. Rohrer B, Guo Y, Kunchithapautham K, Gilkeson GS. Eliminating complement factor $D$ reduces photoreceptor susceptibility to light-induced damage. Invest Ophthalmol Vis Sci. 2007;48:5282-9

37. Rozen S, Skaletsky H. Primer3 on the WWW for general users and for biologist programmers. Methods Mol Biol. 2000;132:365-86.

38. Cornish EE, Madigan MC, Natoli R, Hales A, Hendrickson AE, Provis JM. Gradients of cone differentiation and FGF expression during development of the foveal depression in macaque retina. Vis Neurosci. 2005:22:447-59.

39. Maslim J, Valter K, Egensperger R, Holländer H, Stone J. Tissue oxygen during a critical developmental period controls the death and survival of photoreceptors. Invest Ophthalmol Vis Sci. 1997;38:1667-77.

40. Comerford I, McColl SR. Mini-review series: focus on chemokines. Immunol Cell Biol. 2011;89:183-4.

41. Zhang C, Shen JK, Lam TT, Zeng HY, Chiang SK, Yang F, et al. Activation of microglia and chemokines in light-induced retinal degeneration. Mol Vis. 2005;11:887-95.

42. Natoli R, Zhu Y, Valter K, Bisti S, Eells J, Stone J. Gene and noncoding RNA regulation underlying photoreceptor protection: microarray study of dietary antioxidant saffron and photobiomodulation in rat retina. Mol Vis. 2010;16:1801-22

43. Kohno H, Maeda T, Perusek L, Pearlman E, Maeda A. CCL3 production by microglial cells modulates disease severity in murine models of retinal degeneration. J Immunol. 2014;192:3816-27.

44. Wood LD, Richmond A. Constitutive and cytokine-induced expression of the melanoma growth stimulatory activity/GRO alpha gene requires both NF-kappa B and novel constitutive factors. J Biol Chem. 1995;270:30619-26.

45. Singh PK, Shiha MJ, Kumar A. Antibacterial responses of retinal Muller glia: production of antimicrobial peptides, oxidative burst and phagocytosis. J Neuroinflammation. 2014;11:33.

46. Portillo JA, Van Grol J, Zheng L, Okenka G, Gentil K, Garland A, et al. CD40 mediates retinal inflammation and neurovascular degeneration. J Immunol. 2008:181:8719-26.

47. Elner SG, Delmonte D, Bian ZM, Lukacs NW, Elner VM. Differential expression of retinal pigment epithelium (RPE) IP-10 and interleukin-8. Exp Eye Res. 2006;83:374-9

48. von Toerne C, Menzler J, Ly A, Senninger N, Ueffing M, Hauck SM. Identification of a novel neurotrophic factor from primary retinal Muller cells using SILAC. Mol Cell Proteomics. 2014;13:2371-81.

49. Didier PJ, Paradis TJ, Gladue RP. The CC chemokine MIP-1alpha induces a selective monocyte infiltration following intradermal injection into nonhuman primates. Inflammation. 1999:23:75-86

50. Broxmeyer HE, Sherry B, Cooper S, Lu L, Maze R, Beckmann MP, et al. Comparative analysis of the human macrophage inflammatory protein family of cytokines (chemokines) on proliferation of human myeloid progenitor cells. Interacting effects involving suppression, synergistic suppression, and blocking of suppression. J Immunol. 1993;150:3448-58.

51. Davatelis G, Tekamp-Olson P, Wolpe SD, Hermsen K, Luedke C, Gallegos C, et al. Cloning and characterization of a CDNA for murine macrophage inflammatory protein (MIP), a novel monokine with inflammatory and chemokinetic properties. J Exp Med. 1988;167:1939-44.

52. Weber C, Weber KS, Klier C, Gu S, Wank R, Horuk R, et al. Specialized roles of the chemokine receptors CCR1 and CCR5 in the recruitment of monocytes and $T(H) 1$-like/CD45RO(+) T cells. Blood. 2001;97:1144-6.

53. Broxmeyer HE, Cooper S, Hangoc G, Gao JL, Murphy PM. Dominant myelopoietic effector functions mediated by chemokine receptor CCR1. J Exp Med. 1999;189:1987-92.
54. Amat M, Benjamim CF, Williams LM, Prats N, Terricabras E, Beleta J, et al. Pharmacological blockade of CCR1 ameliorates murine arthritis and alters cytokine networks in vivo. Br J Pharmacol. 2006;149:666-75.

55. Braunersreuther $V$, Zernecke A, Arnaud C, Liehn EA, Steffens S, Shagdarsuren $\mathrm{E}$, et al. $\mathrm{C} c r 5$ but not $\mathrm{Ccr} 1$ deficiency reduces development of diet-induced atherosclerosis in mice. Arterioscler Thromb Vasc Biol. 2007;27:373-9.

56. Zhao Q. Dual targeting of CCR2 and CCR5: therapeutic potential for immunologic and cardiovascular diseases. J Leukoc Biol. 2010;88:41-55.

57. Ishikawa K, Yoshida S, Nakao S, Sassa Y, Asato R, Kohno R, et al. Bone marrow-derived monocyte lineage cells recruited by MIP-1 beta promote physiological revascularization in mouse model of oxygen-induced retinopathy. Lab Invest. 2012;92:91-101.

58. Boring L, Gosling J, Cleary M, Charo IF. Decreased lesion formation in CCR2-/- mice reveals a role for chemokines in the initiation of atherosclerosis. Nature. 1998;394:894-7.

59. Izikson L, Klein RS, Charo IF, Weiner HL, Luster AD. Resistance to experimental autoimmune encephalomyelitis in mice lacking the CC chemokine receptor (CCR)2. J Exp Med. 2000;192:1075-80.

60. Tsou CL, Peters W, Si Y, Slaymaker S, Aslanian AM, Weisberg SP, et al. Critical roles for CCR2 and MCP-3 in monocyte mobilization from bone marrow and recruitment to inflammatory sites. J Clin Invest. 2007;117:902-9.

61. Jia T, Serbina NV, Brandl K, Zhong MX, Leiner IM, Charo IF, et al. Additive roles for MCP-1 and MCP-3 in CCR2-mediated recruitment of inflammatory monocytes during Listeria monocytogenes infection. J Immunol. 2008;180:6846-53

62. Mack M, Cihak J, Simonis C, Luckow B, Proudfoot AE, Plachy J, et al. Expression and characterization of the chemokine receptors CCR2 and CCR5 in mice. J Immunol. 2001;166:4697-704.

63. Ribeiro $\mathrm{S}$, Horuk R. The clinical potential of chemokine receptor antagonists. Pharmacol Ther. 2005;107:44-58.

64. Eash KJ, Greenbaum AM, Gopalan PK, Link DC. CXCR2 and CXCR4 antagonistically regulate neutrophil trafficking from murine bone marrow. J Clin Invest. 2010;120:2423-31.

65. Opdenakker G, Fibbe WE, Van Damme J. The molecular basis of leukocytosis. Immunol Today. 1998;19:182-9.

66. Burdon PC, Martin C, Rankin SM. Migration across the sinusoidal endothelium regulates neutrophil mobilization in response to $\mathrm{ELR}+\mathrm{CXC}$ chemokines. $\mathrm{Br} \mathrm{J}$ Haematol. 2008;142:100-8.

67. Koch AE. Chemokines and their receptors in rheumatoid arthritis: future targets? Arthritis Rheum. 2005;52:710-21

68. Koch AE, Kunkel SL, Shah MR, Hosaka S, Halloran MM, Haines GK, et al. Growth-related gene product alpha. A chemotactic cytokine for neutrophils in rheumatoid arthritis. J Immunol. 1995;155:3660-6.

69. Reutershan J, Morris MA, Burcin TL, Smith DF, Chang D, Saprito MS, et al. Critical role of endothelial CXCR2 in LPS-induced neutrophil migration into the lung. J Clin Invest. 2006;116:695-702.

70. Chintakuntlawar AV, Chodosh J. Chemokine CXCL1/KC and its receptor CXCR2 are responsible for neutrophil chemotaxis in adenoviral keratitis. J Interferon Cytokine Res. 2009;29:657-66.

71. Zhou J, Pham L, Zhang N, He S, Gamulescu MA, Spee C, et al. Neutrophils promote experimental choroidal neovascularization. Mol Vis. 2005;11:414-24

72. Zhou J, He S, Zhang N, Spee C, Zhou P, Ryan SJ, et al. Neutrophils compromise retinal pigment epithelial barrier integrity. J Biomed Biotechnol. 2010;2010:289360.

73. Soehnlein O, Drechsler M, Doring $Y$, Lievens D, Hartwig $H$, Kemmerich $K$ et al. Distinct functions of chemokine receptor axes in the atherogenic mobilization and recruitment of classical monocytes. EMBO Mol Med. 2013:5:471-81.

74. Boisvert WA, Rose DM, Johnson KA, Fuentes ME, Lira SA, Curtiss LK, et al. Up-regulated expression of the CXCR2 ligand KC/GRO-alpha in atherosclerotic lesions plays a central role in macrophage accumulation and lesion progression. Am J Pathol. 2006;168:1385-95.

75. Lindner M, Trebst C, Heine S, Skripuletz T, Koutsoudaki PN, Stangel M. The chemokine receptor CXCR2 is differentially regulated on glial cells in vivo but is not required for successful remyelination after cuprizone-induced demyelination. Glia. 2008:56:1104-13.

76. Goczalik I, Ulbricht E, Hollborn M, Raap M, Uhlmann S, Weick M, et al. Expression of CXCL8, CXCR1, and CXCR2 in neurons and glial cells of the human and rabbit retina. Invest Ophthalmol Vis Sci. 2008;49:4578-89. 
77. Klein RS, Lin E, Zhang B, Luster AD, Tollett J, Samuel MA, et al. Neuronal CXCL10 directs CD8+ T-cell recruitment and control of West Nile virus encephalitis. J Virol. 2005;79:11457-66

78. Zhang B, Chan YK, Lu B, Diamond MS, Klein RS. CXCR3 mediates region specific antiviral T cell trafficking within the central nervous system during West Nile virus encephalitis. J Immunol. 2008;180:2641-9.

79. Norose K, Kikumura A, Luster AD, Hunter CA, Harris TH. CXCL10 is required to maintain T-cell populations and to control parasite replication during chronic ocular toxoplasmosis. Invest Ophthalmol Vis Sci. 2011;52:389-98.

80. Vargas-Inchaustegui DA, Hogg AE, Tulliano G, Llanos-Cuentas A, Arevalo J, Endsley JJ, et al. CXCL10 production by human monocytes in response to Leishmania braziliensis infection. Infect Immun. 2010;78:301-8.

81. Nieto JC, Canto E, Zamora C, Ortiz MA, Juarez C, Vidal S. Selective loss of chemokine receptor expression on leukocytes after cell isolation. PLoS One. 2012;7:e31297

82. Flynn G, Maru S, Loughlin J, Romero IA, Male D. Regulation of chemokine receptor expression in human microglia and astrocytes. J Neuroimmunol. 2003;136:84-93.

83. Joly S, Francke M, Ulbricht E, Beck S, Seeliger M, Hirrlinger $P$, et al. Cooperative phagocytes: resident microglia and bone marrow immigrants remove dead photoreceptors in retinal lesions. Am J Pathol. 2009;174:2310-23.

84. Oh JW, Schwiebert LM, Benveniste EN. Cytokine regulation of CC and CXC chemokine expression by human astrocytes. J Neurovirol. 1999:5:82-94.

85. Roach DR, Bean AG, Demangel C, France MP, Briscoe H, Britton WJ. TNF regulates chemokine induction essential for cell recruitment, granuloma formation, and clearance of mycobacterial infection. J Immunol. 2002;168:4620-7.

86. Ramesh G, Reeves WB. TNF-alpha mediates chemokine and cytokine expression and renal injury in cisplatin nephrotoxicity. J Clin Invest. 2002;110:835-42.

87. Calkins CM, Bensard DD, Shames BD, Pulido EJ, Abraham E, Fernandez N et al. IL-1 regulates in vivo C-X-C chemokine induction and neutrophil sequestration following endotoxemia. J Endotoxin Res. 2002;8:59-67.

88. Chou RC, Kim ND, Sadik CD, Seung E, Lan Y, Byrne MH, et al. Lipid-cytokinechemokine cascade drives neutrophil recruitment in a murine model of inflammatory arthritis. Immunity. 2010;33:266-78.

89. Niebuhr M, Baumert K, Werfel T. TLR-2-mediated cytokine and chemokine secretion in human keratinocytes. Exp Dermatol. 2010;19:873-7.

90. Kochan T, Singla A, Tosi J, Kumar A. Toll-like receptor 2 ligand pretreatment attenuates retinal microglial inflammatory response but enhances phagocytic activity toward Staphylococcus aureus. Infect Immun. 2012;80:2076-88.

91. Chen CJ, Shi Y, Hearn A, Fitzgerald K, Golenbock D, Reed G, et al. MyD88dependent IL-1 receptor signaling is essential for gouty inflammation stimulated by monosodium urate crystals. J Clin Invest. 2006;116:2262-71.

92. Jia T, Leiner I, Dorothee G, Brandl K, Pamer EG. MyD88 and Type I interferon receptor-mediated chemokine induction and monocyte recruitment during Listeria monocytogenes infection. J Immunol. 2009;183:1271-8.

93. Wang M, Ma W, Zhao L, Fariss RN, Wong WT. Adaptive Muller cell responses to microglial activation mediate neuroprotection and coordinate inflammation in the retina. J Neuroinflammation. 2011:8:173.

94. Ma W, Zhao L, Fontainhas AM, Fariss RN, Wong WT. Microglia in the mouse retina alter the structure and function of retinal pigmented epithelial cells: a potential cellular interaction relevant to AMD. PLoS One. 2009:4:e7945.

\section{Submit your next manuscript to BioMed Central and take full advantage of:}

- Convenient online submission

- Thorough peer review

- No space constraints or color figure charges

- Immediate publication on acceptance

- Inclusion in PubMed, CAS, Scopus and Google Scholar

- Research which is freely available for redistribution

Submit your manuscript at www.biomedcentral.com/submit 